\section{Reflexiones en torno a los sitios de memoria en Uruguay: las demarcaciones del paisaje represivo}

\author{
Luciana Scaraffuni [*] \\ [*] Docente e investigadora, Facultad de Ciencias \\ Sociales, Universidad de la Republica Oriental del \\ Uruguay (Udelar). Montevidéu, Uruguai. luciana. \\ scaraffuni@cienciassociales.edu.uy
}

ORCID: https://orcid.org/0000-0002-2571-9068
Resumen: En el marco de los esfuerzos por delimitar o demarcar algunos lugares de memoria, con el fin de no perder esas huellas dentro de la construcción de memoria colectiva en torno a lo que fue la dictadura cívico-militar uruguaya (19731985), se vuelve inteligible en la ciudad de Montevideo la existencia de algunos sitios de memoria que fueron creados a partir de la ley 19.641 aprobada en julio de 2018, configurando determinados paisajes de la memoria. Este artículo busca reflexionar acerca del establecimiento de estos sitios, con el fin de exponer la lógica de la demarcación y del recuerdo. Hace hincapie en uno de ellos el centro comercial Punta Carretas Shopping, que funcionó como cárcel y ha sido parte de un proceso complejo de demarcación que responde al neoliberalismo. Este artículo busca exponer los debates que encierran estas demarcaciones, las diferentes concepciones y las configuraciones que termina adoptando la ciudad de Montevideo.

Palabras clave: Sitios de Memoria; Sitios de Olvido; Huellas.

\section{Reflexões sobre lugares de memória no Uruguai: as demarcações da paisagem repressiva}

Resumo: Dentro dos esforços para delimitar ou demarcar alguns lugares de memória, para não perder esses vestígios na construção da memória coletiva em torno do que foi a ditadura cívico-militar uruguaia (1973-1985), torna-se inteligível na cidade de Montevidéu a existência de alguns sítios de memória que foram criados a partir da lei 19.641 aprovada em julho de 2018, configurando certas paisagens de memória. Este artigo busca refletir sobre a constituição e contexto desses sítios, a fim de expor a lógica da demarcação e da memória, frente a lógica do esquecimento. Um deles é o centro comercial Shopping Punta Carretas, que funcionou como uma prisão e fez parte de um complexo processo de demarcação que corresponde ao neoliberalismo, serviu de veículo para a memória do consumismo. Este artigo busca expor os debates que cercam essas demarcações, as diferentes concepções e configurações que a cidade de Montevidéu acaba adotando diante do passado recente.

Palavras-chave: Lugares de Memória; Lugares de Esquecimento; Paisagens de Memória. 


\section{Introduccion}

Dentro del campo de estudios sobre el Pasado Reciente, el que involucra estudios acerca de lo acontecido en las ultimas dictaduras civico-militares vividas en los países del Cono Sur, la reflexión y el análisis acerca de los sitios de memoria que marcan las huellas materiales de los hechos acontecidos ha ocupado un lugar principal en países como Argentina, Chile y Brasil, ha sido fundamental para el análisis de los trabajos sobre la memoria y las culturas del recuerdo.

En Uruguay el análisis acerca de los sitios de memoria ha sido desarrollado de forma no tan central, como sí lo ha sido el abordaje de otros aspectos acerca de lo acontecido, siendo que hay pocos trabajos desde el ámbito académico que nos permitan analizar como fue este proceso.

Entre algunos esfuerzos que se han realizado en la academia uruguaya por reflexionar sobre este tema en estos últimos años, podemos situar a Guglielmucci y Scaraffuni (2016), Susana Draper (2011), María Eugenia Allier Montaño (2008) y al ensayista y escritor Hugo Achugar (2003), quienes han promovido el análisis y el debate en torno a delimitar y clasificar los "lugares de memoria" que hacen referencia al Pasado Reciente en la ciudad de Montevideo. En el artículo "Site of memory and site of forgetting the repurposing of the Punta Carretas Prison" publicado en Latin American Perspectives, durante el año 2016, que escribí junto con Ana Guglielmucci, planteamos en base a algunas investigaciones y publicaciones, que las delimitaciones del espacio y la demarcación de los lugares, no son simplemente un producto gubernamental, si no que son el resultado de las construcciones y representaciones de los movimientos sociales y de los movimientos de victimas (Scaraffuni, Guglielmucci, 2016, p. 132).

Este tema en Uruguay no está abordado como se debe, ni por el ámbito académico, ni por el ámbito estatal. Se debe señalar que hasta el año 2018 en Uruguay no se contaba con una Ley de Creación de Sitios de Memoria Histórica del Pasado Reciente, la promulgación de la misma fue el 13 de julio de 2018, mientras que su publicación oficial fue el 14 de agosto de 2018 .

La ley tiene por objeto la "declaración y creación de Sitios de Memoria Histórica del Pasado Reciente de la República Oriental del Uruguay", la "declaración y creación de Sitio de Memoria Histórica consagra el recordatorio y reconocimiento de aquellos lugares donde las personas víctimas de terrorismo o accionar ilegítimo del Estado sufrieron violaciones a sus derechos humanos por motivos políticos, ideológicos o gremiales y que son utilizados

Artículo 1 (Objeto), Ley n. 19.641 
como espacios abiertos al público para la recuperación, construcción y transmisión de memorias, así como forma de homenaje y de reparación a las víctimas y a las comunidades."

Según el Artículo 4 comprendido en la ley se considera sitios de memoria: "aquellos espacios físicos donde se verificaron alguno o algunos de estos acontecimientos: a) la ocurrencia de violaciones a los derechos humanos por parte del Estado, comprendiendo delitos de lesa humanidad tales como la tortura, desaparición forzada, homicidio político, prisión indebida, violaciones y otros delitos sexuales contra hombres y mujeres, persecución política, destituciones o exilio; b) la realización de actos de resistencia y lucha por la construcción o recuperación democrática; c) otros sitios a los cuales las víctimas, familiares o las comunidades los asocian con esos acontecimientos y que han sido creados para construir y transmitir memorias, tales como memoriales, museos y otros espacios y que son utilizados como espacios abiertos al público para la recuperación, construcción y trasmisión de memorias, así como forma de homenaje y de reparación a las víctimas y a las comunidades." ${ }^{3}$

El período que se encuentra comprendido para la demarcación de los Sitios de Memoria abarca según el Artículo 5 de la ley "desde el 13 de junio de 1968 hasta el 26 de junio de 1973, en el marco de la aplicación sistemática de las Medidas Prontas de Seguridad y bajo los preceptos de la Doctrina de la Seguridad Nacional imperante. Y el comprendido desde el 27 de junio de 1973 hasta el 28 de febrero de 1985, período en que se instauró la dictadura cívico-militar", aunque también se "podrán considerar hechos acontecidos fuera de los períodos antes mencionados en los que el Estado haya violado los derechos humanos o donde haya habido expresiones significativas de resistencia popular".

La ley crea la existencia de una Comisión Honoraria de Sitios de Memoria integrada por nueve miembros: "Un delegado de la Institución Nacional de Derechos Humanos y Defensoría del Pueblo, que la presidirá. Un delegado del Ministerio de Educación y Cultura. Un delegado de la Universidad de la República. Un delegado de la Administración Nacional de Educación Pública. Dos delegados de dos organizaciones sociales destacadas en la lucha por la memoria y los derechos humanos, inscriptas en el Registro de organizaciones sociales de la Institución Nacional de Derechos Humanos y Defensoría del Pueblo, que serán electos en una instancia presencial convocada a tales efectos por dicha institución, Tres delegados de la Red Nacional de Sitios de Memoria."

Esta ley además de su propósito educativo y de dar a conocer el Pasado Reciente, permite resignificar espacios, lugares, recuperar y vehiculizar hacia la sociedad información para la construcción de la memoria colectiva y para el avance de las investigaciones acerca

\footnotetext{
2 Artículo 3 (Recordatorio y reconocimiento), Ley n. 19.641.

3 Artículo 4 (Definición), Ley n. 19.461.

${ }^{4}$ Artículo 9 (Integración), Ley n. 19.461.
} 
del período de la última dictadura cívico-militar (1968-1985). El establecimiento de esta ley en 2018, tuvo como objetivo de parte del último gobierno de izquierda que tuvo Uruguay, generar una política pública de memoria que evidenciara lugares en la ciudad de Montevideo donde habían sucedido hechos de resistencia, secuestro, tortura, durante este período.

Se demarcaron varios lugares en la ciudad de Montevideo, específicamente hay un lugar que no fue considerado, ni demarcado por esta ley y es el que se conoce como Shopping Punta Carretas.

Este artículo busca revisitar algunas reflexiones elaboradas en el articulo "Site of memory and site of forgetting the repurposing of Punta Carretas Prison" en el año 2016, teniendo en cuenta que es recién durante el mes de febrero de $2020^{5}$ que se colocó la primera piedra fundamental para lo que a largo plazo deberá ser un memorial con los nombres de quienes pasaron por la cárcel de Punta Carretas, lo que hoy en día se conoce como el Shopping Punta Carretas.

Asimismo y a través de volver sobre algunas reflexiones y teorizaciones previas se trasluce el estado de poco avance teórico de la academia uruguaya en torno al planteamiento de estos temas.

\section{Las interacciones con el espacio: formas de trascender los "lugares de memoria" o de "amnesia"}

En primer lugar se debe tener en cuenta que cada dictadura en los diferentes países del Cono Sur, presentó características especificas, en Uruguay el régimen se caracterizo por la prisión prolongada y por la tortura, esto convirtió a Uruguay en el país con el mayor índice de presos en torno a la población que tenia (Lessa, Druliolle, 201l; Allier Montaño, 2015).

Según la investigación histórica sobre detenidos-desaparecidos realizada en el ámbito estatal a partir del año 2005 y hasta el 2019, se publicaron cuatro tomos en torno a varios aspectos abordados acerca de las características del régimen, a grandes rasgos se puede destacar que entre los meses de junio de 1973 (el comienzo del régimen) y marzo de 1985 (el inicio de la transición democrática) hubo 5.925 presos políticos hombres en el penal de Libertad (Establecimiento Militar de Reclusión 1) y 739 mujeres presas políticas en Punta de Rieles (Establecimiento Militar de Reclusión; 2) mientras que también hubo 186 mujeres presas en la cárcel de Paso de los Toros. ${ }^{6}$

\footnotetext{
${ }^{5}$ Véase <https://www.sau.org.uy/piedra-fundamental-memorial-punta-carretas/>.

${ }^{6}$ Rico, A. (Coord.), Investigación histórica sobre detenidos-desaparecidos, Presidencia de la República, IMPO, 4 tomos, Montevideo, 2007-2011.
} 
Esto nos posiciona frente al hecho de que el aparato represivo de la dictadura uruguaya, estuvo vinculado a lugares y espacios de detención y a la profesionalización de prácticas de tortura en dichos lugares.

Un proyecto que intenta avanzar en el camino de la identificación de lugares vinculados a la detención y tortura de la población durante este período es el trabajo realizado por el sitio web Sitios de Memoria en Uruguay, ${ }^{7}$ que busca cartografiar los espacios que oficiaron como lugares de detención y tortura.

Retomando algunas reflexiones sobre las que he trabajado previamente, se debe tener en cuenta que la memoria no constituye un proceso que esté exclusivamente fijado al espacio, entendido como materialidad exterior, condensada e inmóvil (aunque indiscutiblemente el espacio sirva como soporte mnemotécnico). Si no que y particularmente en ese lugar, el movimiento de los cuerpos genera una interacción entre el sitio y quienes lo transitan, lo que logra configurar un espacio de memoria cultural ligado a los itinerarios trazados e incorporados (Scaraffuni y Guglielmuci, 2016). En este sentido, resulta relevante subrayar la advertencia de Paul Connerton (2009) sobre la noción que nuestras sociedades tienen acerca del espacio, que siempre han tendido a pensarlo como algo fijo y estático, lo que de algún modo explicaría la demarcación o delimitación de la memoria a un lugar específico. De hecho es común suponer que, para que la memoria esté presente ella debe estar explicitada, fija y delimitada en un lugar o repositorio, lo que se traduce en lo que ha sido una creciente musealización o demarcación de la memoria en algunos países, incluyendo a Uruguay con el Museo de la Memoria que comienza a funcionar en el año 2007. Esta concepción predominante acerca de la relación entre memoria, espacio y materialidad, ha llevado a suponer algunas veces que la ausencia de iniciativas gubernamentales de señalización o demarcación de un lugar en tanto "sitio de memoria" es equivalente a la imposibilidad de hacer eco a través de la rememoración de quienes lo transitan o a la falta de tramitación social sobre el Pasado Reciente.

Cabe destacar que Uruguay tuvo un proceso muy distinto con respecto a la tramitación de ese Pasado Reciente y a la demarcación de los lugares de memoria como sucedió en Argentina por ejemplo, en el cual hubo un fuerte proceso social de producción de la categoría "memoria sobre el terrorismo de Estado" que fue objeto de políticas públicas estatales en la Ciudad de Buenos Aires y que se tradujo sobre todo en la la demarcación espacial y en la exhibición de un pasado "invisibilizado" (Guglielmucci, 2013; Draper, 2011).

Si bien, en Uruguay entre los años 1985 a 1989 se re-funcionalizaron la mayoría de los espacios que habían sido utilizados para estos propósitos, muchos siguen cumpliendo las mismas funciones aun al día de hoy.

${ }^{7}$ Véase <https://sitiosdememoria.uy/montevideo> 
Sobre este aspecto y haciendo referencia al caso anteriormente mencionado (el del Punta Carretas Shopping) resulta importante mostrar las prácticas que habilitan a la construcción de este espacio material, donde no había en primera instancia una señalización, hasta hace seis meses atrás. En esa resignificacion del espacio, donde los transeúntes y consumidores tienen un relacionamiento específico con el lugar, en base al consumo conspicuo, a la erotización de los objetos expuestos en vidrieras, es decir, es un lugar que configura narrativas y representaciones simbólicas fuertes, que establecen nexos entre los sujetos y el espacio.

La transformación de la cárcel de Punta Carretas en un shopping center acompañó los cambios económicos, políticos y culturales ligados a políticas neoliberales - consolidadas a fines de los 1980 y adentrados los 1990 - implementadas luego de una serie de dictaduras militares en América Latina. Esta transformación responde a un sistema organizativo que configura nuevas formas de relacionamiento social y cultural, en torno a la búsqueda de satisfacción de las necesidades de consumo de los individuos. Pero, a su vez, resulta llamativo que pone en juego la re-funcionalización del espacio a través de una arquitectura que puede ser considerada como un "palimpsesto", es decir, como formas arquitectónicas pasadas superpuestas a nuevas refacciones presentes (Harvey, 1998; Achugar, 2004; Guglielmuci y Scaraffuni, 2016).

Si pensamos en el shopping, teniendo en cuenta esta re-significación del espacio, no podemos afirmar que allí no circulan o no se configuran memorias distintas. Desde su propio nombre, que continúa siendo el mismo, y teniendo en cuenta que cada espacio alimenta distintas construcciones de recuerdos a través de ciertas disposiciones en los cuerpos (Connerton, 2009), debemos considerar que este lugar, resignificar las relaciones entre las personas dentro del mismo espacio, así como con su hábitat, es decir, con el barrio y con la ciudad de Montevideo.

El establecimiento de la piedra fundamental busca plasmar desde una política pública, que comenzó a implementarse durante el último año de gobierno de izquierda, tiene como finalidad demarcar y plasmar determinados sentidos y representaciones del espacio y en el espacio. Se impone una trama de significaciones en el espacio, lo cual lo determinan como un lugar de memoria.

Cabe destacar, que el espacio del Punta Carretas Shopping genera ciertas dinámicas corporales, continuas en el espacio, tal como lo hacía cuando era una cárcel, refiriéndonos a Foucault podemos decir que "el cuerpo queda prendido en el interior de poderes muy ceñidos, que le imponen coacciones, interdicciones u obligaciones" (Foucault, 1998, p. 140). En el shopping se genera una organización de los movimientos dentro del espacio, rodeados de amplias superficies vidriadas, escaleras mecánicas y ascensores que guían los cuerpos. Si bien la cárcel y el shopping generan experiencias y relaciones espaciales distintas, que están relacionadas con el cambio arquitectónico de la modernidad (Jameson, 2010), a su vez, no 
se deja de producir un determinado "ejercicio" en los cuerpos, a través de una coerción, haciendo al individuo obediente y útil a los cometidos del espacio (Foucault, 1998).

Se debe considerar que tanto cuando era cárcel como luego de su refuncionalización, el espacio ofició como generador de disciplinamientos sobre los cuerpos, donde los cuerpos entran en una relación de poder que los significa y resignifica, haciéndolos útiles a los cometidos de la refuncionalización de este lugar.

Esto nos pauta que es un espacio con diferentes relaciones en torno a las memorias que produce y reproduce o resignifica, en este proceso de refuncionalización no queda por fuera la memoria, ya que en esa interacción de los cuerpos con el espacio, la memoria se va configurando en los cuerpos también. Es decir, se genera un disciplinamiento de la memoria en los cuerpos y de esta en el espacio, teniendo en cuenta que en la actualidad, tanto como cuando era cárcel, se busca que los cuerpos hagan lo que se pretende que hagan (Guglielmuci y Scaraffuni, 2016). De este modo, se genera una comunicación entre los cuerpos que lo visitan, haciendo que estos se apropien y desplieguen en el espacio y lo integren al día a día, los cuerpos incorporan ese lugar a sus movimientos habituales y cotidianos, lo cual genera a su vez una memoria internalizada del lugar (Connerton, 2009).

Podemos decir que con la huella o la demarcación se logra poner la atención en el Punta Carretas como sitio testimonial del Pasado Reciente, configurándose como un sitio que presenta otro relato además del que presenta el shopping center, relatos de ese pasado.

Si bien hubo mucha dificultad para comenzar el proceso de demarcación por parte de las organizaciones de víctimas, esta demarcación hace rendir cuentas sobre ese pasado, busca relacionar a la sociedad con su historia, intenta "resolver" esa relación, pero esto nos pone frente a la situación de iqué sucede luego que estos lugares son demarcados?, es decir, ahora que el shopping tiene una primera demarcación lo cual define un proceso de "recuperación" de ciertas narrativas y relatos del lugar, ¿qué sucede luego que es demarcado como sitio de memoria?.

\section{El desafío en los proceso de demarcación: ies importante la institucionalización de la memoria?}

En el período que va desde 2005 a 2018 el Estado uruguayo tuvo avances en el terreno de la reparación simbólica a las víctimas y sus familiares, ha logrado en términos demarcatorios instalar algunas placas en lugares que fueron centros de detención y tortura. A su vez, recuperó algunos sitios que habían funcionado como oficinas del servicio de inteligencia del Estado, entre otros. En el mes de enero de 2010 comenzó a implementarse la Ley n. 18.596 (Ley de Reparación), la cual creó en el ámbito del Ministerio de Educación y Cultura la 
Comisión Especial de Reparación. Esta ley buscaba reparar en términos simbólicos y económicos a víctimas y/o familiares de víctimas del terrorismo de Estado (enmarcado entre el 27 de junio de 1973 al 28 de febrero de 1985) y/o del accionar ilegítimo del Estado (entre el 13 de junio de 1968 y el 26 de junio de 1973). ${ }^{8}$

Las primeras demarcaciones o más específicamente marcas en el paisaje urbano, se realizan en el año 2015 a través de un proyecto denominado "Marcas de la memoria en Uruguay" ${ }^{9}$ llevado a cabo por la Central Sindical, la Facultad de Arquitectura y la organización civil Asociación Memoria de la Resistencia 1973-1985.

Pero este camino de demarcaciones ha sido complejo y visibiliza las dinámicas y dificultades de la impunidad y de los sucesivos gobiernos de izquierda de estos últimos años (2005-2019) en relación a la configuración de una cultura del recuerdo que relacione los espacios y las experiencias vinculadas a ese Pasado Reciente.

Retomando el debate en torno a los conceptos expuestos lugar de memoria o lugar de amnesia como se ha definido por décadas al lugar del Punta Carretas Shopping, se debe reconocer que esto, no nos permite leer las memorias y entrelíneas que hasta el día de hoy confluyen allí, lo cual nos lleva a pensar que debemos deslocalizar nuestras preguntas, no hacerlas dependientes de una demarcación específica del espacio, aunque ahora la tenga.

Es decir, los debates en torno a la memoria en el Cono Sur han estado marcados por una perspectiva hegemonizada por la relación entre espacios, recuerdo y olvido. Esto ha impedido vislumbrar los intersticios de la memoria, que van más allá de lo que se muestra o se demarca, se exhibe o se deja de lado, en un espacio determinado.

La memoria opera de maneras escurridizas y a veces a través de redes subterráneas. Podemos destacar que hay regímenes oficiales de memoria que se intentan construir a través de la implementación gubernamental de políticas públicas de recuerdo-olvido sobre el pasado. Pero, ello no basta para que estas políticas de recuerdo-olvido sean encarnadas en nuestra subjetividad y se anclen en nuestras propias representaciones de la vida en común. Tal vez, el edificio del Punta Carretas, convertido en shopping center, no haya mostrado su historia pasada como cárcel hasta febrero de 2020, pero permitió vivenciar formas de relacionarse signadas por amplios cambios socio-económicos y deja ver otros pasados posibles en los intersticios del lugar.

Si entendemos el espacio como un palimpsesto, un manuscrito antiguo que conserva huellas de una escritura anterior que fue borrada, la localización espacial de la memoria se vuelve un recurso entre otros para pensar e, incluso, intervenir en el recuerdo colectivo.

\footnotetext{
8 Véase <https://www.gub.uy/ministerio-educacion-cultura/politicas-y-gestion/comision-especial-reparacion>.

9 Véase <http://www.fadu.edu.uy/idd/files/2019/10/Marcas-de-la-Memoria-de-la-Resistencia.pdf>.
} 
Hay diferentes significados políticos, sociales, que intervienen en la demarcación y por ende en la construcción de la memoria colectiva asociada a los sitios de memoria.

La concreción de la demarcación del edificio fue muy prolongada en el tiempo, pero fue a partir de la apropiación de las organizaciones de ex presos que se realizó la demarcación, dejando en evidencia ese otro relato que no estaba propiamente identificado en el territorio. Esto nos posiciona frente a la evidencia de otras formas de narrar la memoria de ese lugar, que si bien pueden estar implícitas en el nombre o en el recuerdo de los habitantes del barrio, no estaban visibles en el territorio. Son placas o carteles, es decir, marcas que buscan darle un soporte material a la memoria del Pasado Reciente y hacerla visible.

Estas señalizaciones o huellas, que configuran los paisajes de memoria de la ciudad de Montevideo, han transformado en este último año, algunos lugares específicos, les han dado significados relacionados a eventos de ese Pasado Reciente que está presente en lo urbano, y sobre todo, las organizaciones de víctimas han podido enmarcar su relato o narración en un espacio físico determinado, los sujetos referencian allí sus experiencias.

En este sentido, el lugar de memoria se configura como resultado de acciones y de iniciativas de las organizaciones de ex presos y de emprendedores estatales de la memoria, la marca o la piedra fundamental es significativa para la construcción de memoria colectiva, basada en otra narrativa sobre el pasado.

Este lugar específicamente, tiene sus demandas de demarcación, por lo cual se espera que el memorial que se va a construir a largo plazo allí sea un recordatorio de quienes estuvieron presos. La iniciativa si bien surge de colectivos de ex presos, tuvo el apoyo del Poder Ejecutivo, la Intendencia de Montevideo, la Institución Nacional de Derechos Humanos y la Defensoría del Pueblo.

Las luchas por demarcar territorialmente la memoria de este lugar, también fueron luchas de significados, ya que si bien hay un conocimiento de las funcionalidades que tuvo el edificio, fue un camino largo el lograr colocar la primer marca. Por un lado hay demandas de la empresa que no permite que se realice ningún tipo de demarcación dentro del edificio, por ende, la demarcación se realiza afuera en un área pública y con espacios verdes. Esta acción responde a las decisiones del último gobierno de izquierda que buscó generar una "cultura del recuerdo", frente al discurso establecido por los partidos conservadores y de derecha con respecto que hubo una guerra entre dos bandos.

Este lugar se transforma así en soporte de recuerdos y construcciones identitarias, a través del reconocimiento de dicho edificio. Si bien, no podemos dejar de señalar que las demarcaciones en ese paisaje urbano, se corresponde con ciertas selecciones o recortes lo cual determinarían algunos sentidos del lugar, la construcción de memoria está atravesada por estas decisiones. 


\section{Consideraciones finales}

Retomando lo planteado al principio de este artículo y en base a las reflexiones sobre las cuales me posiciono para analizar hoy en día la demarcación de un espacio tan conocido para la sociedad uruguaya como el Punta Carretas Shopping, no se puede dejar de reconocer o de reflexionar en torno a que las construcciones de memoria que se configuraron en ese espacio, han sido variadas, han respondido a diferentes dinámicas de relacionamiento de los sujetos con el espacio y no necesariamente han dejado de lado el reconocimento del edificio como ex cárcel por algunas porciones de la sociedad uruguaya.

En base a esto, se debe reflexionar sobre los criterios de espacialización de la memoria en lugares públicos como planteó Susana Draper (2011), si bien hay una necesidad en las sociedades de reconocer y de cierta forma integrar ese Pasado Reciente a través de huellas demarcatorias a lo urbano, se debe tener en cuenta que la memoria que se configura en ese espacio hace visible y sitúa algunos aspectos mientras omite o deja de lado otros.

Particularmente, el Punta Carretas Shopping fue categorizado por mucho tiempo como un lugar de amnesia, hoy podríamos reconocer que es un lugar que está disponible como futuro sitio de memoria en pos de organizar y re-organizar el pasado (Candau, 2002), la memoria se configura y se enmarca en el territorio que la condensa, pero también va a dialogar con las memorias que ese mismo espacio generó en su dinámica como shopping.

Con respecto a esto, no se está cuestionando la demarcación en sí, si no que se busca reflexionar sobre el hecho de "hacer memoria", de reconocer ese lugar, de reconocer que en ese espacio hubo determinadas dinámicas y experiencias y que estas se entrecruzan con las actuales y eso está presente en un proceso dialéctico y continuo de olvido/memoria (Candau, 2002; Halbwachs, 1968; Guglielmuci y Scaraffuni, 2016).

Todo recuerdo o remembranza que busca ser señalizado o visibilizado involucra un proceso de selección acerca de lo que fue el lugar, lo que es y lo que se espera que sea en torno a esa construcción de memoria. El shopping necesariamente no ha sido un lugar de amnesia como fuera catalogado, en base a trabajo de campo realizado podemos señalar que los habitantes del barrio y algunos visitantes del centro comercial recordaban muy bien que ese edificio había sido una cárcel. Esto nos lleva a reflexionar si no sería más interesante plantearnos cuáles son las representaciones de ese edificio para los habitantes del barrio y icómo dialogan con las cotidianeidades de los vecinos y de quienes visitan o trabajan en el shopping?

Se torna necesario resaltar que la interrelación de ambos planos (el de shopping y el de cárcel) tienen cierta correspondencia, dado que buscan de alguna forma homogeneizar ciertas temporalidades habilitando nuevas posibilidades de relacionamiento con el espacio que permitió el neoliberalismo (Draper, 2012; Guglielmuci y Sacaraffuni, 2016).

Si bien, como varios autores han destacado, la construcción de la memoria colectiva o 
de la cultura del recuerdo es sin duda un campo en disputa, hoy en día Uruguay está frente a un nuevo embate conservador y represivo, debido a que hay una derecha militarista instaurada en el poder que ha vuelto a poner sobre la mesa la reivindicación de la Ley de Caducidad y Pretensión punitiva del Estado, que cuestiona a la justicia en torno a los procesamientos realizados a miembros de las Fuerzas Armadas y que busca revisitar los libros de historia utilizados en el ámbito de la enseñanza para reformular el relato histórico del Pasado Reciente, en pos de integrar su visión de los hechos.

Esto hace que la construcción de memoria colectiva y el proceso de demarcación de sitios comience una nueva etapa en la que sin dudas se buscarán imponer nuevos símbolos, imaginarios y representaciones en torno a un Pasado Reciente que aún no ha dejado de pasar.

\section{Referencias}

ACHUGAR, Hugo. El lugar de la memoria, a propósito de monumentos (Motivos y paréntesis). In: JELIN, Elizabeth; LANGLAND, Victoria (Eds.) Monumentos, memoriales y marcas territoriales. Madrid: Siglo XXI, 2003. p. 191-216.

ACHUGAR, Hugo. Territorios y memoria versus lógica del mercado: a propósito de cartografías y shopping malls. En: ACHUGAR, Hugo (Ed.). Planetas sin boca: escritos efímeros sobre arte, cultura y literatura. Montevideo: Trilce, 2004. p. 117-228.

ALLIER MONTAÑO, Eugenia. Lugar de memoria: ¿un concepto para el análisis de las luchas memoriales? El caso de Uruguay y su Pasado Reciente. Cuadernos del CLAEH (Montevideo). año 31, n. 96-97, 2 $2^{\text {a }}$ serie, p. 87-109, 2008.

ALLIER MONTAÑO, Eugenia. De historias y memorias sobre el Pasado Reciente en Uruguay: treinta años de debates. Caravelle [online], n. 104, 6 oct. 2015. Disponible en: 〈http://journals.openedition.org/caravelle/1615〉. Consultado: 29 ago. 2020. DOI: https:// doi.org/10.4000/caravelle.1615.

CANDAU, Joël. Antropología de la memoria. Buenos Aires: Nueva Visión, 2002.

CONNERTON, Paul. How modernity forgets. Cambridge: Cambridge University Press, 2009.

DRAPER, Susana. De cárceles y museos: alas, itinerarios artísticos y encuadre de temporalidades. Con- temporánea: Historia y Problemas del Siglo XX (Montevideo). v. 2, año 2, p. 183-201, 2011.

DRAPER, Susana. Afterlives of confinement: spatial transitions in postdictatorship Latin America. Pittsburgh: University of Pittsburgh Press, 2012.

FOUCAULT, Michel. Vigilar y castigar: nacimiento de la prisión. México: Siglo XXI, 1998.

GUGLIELMUCCI, Ana. La consagración de la memoria: una etnografía acerca de la institucionalización del recuerdo sobre los crímenes del terrorismo de Estado en la Argentina. Buenos Aires: Antropofagia, 2013.

GUGLIELMUCCI, Ana; SCARAFFUNI, Luciana. Site of memory and site of forgetting: the repurposing of the Punta Carretas Prison. Latin American Perspectives. v.43, n. 5, 2016.

HALBWACHS, Maurice. La mémoire collective. Paris: PUF, 1968.

HARVEY, David. La condición de la posmodernidad: investigación sobre los orígenes del cambio cultural. Buenos Aires: Amorrortu, 1998.

JAMESON, Frederic. El giro cultural: escritos seleccionados sobre el posmodernismo, 1983-1998. Buenos Aires: Manantial, 2010.

LESSA, Francesca; DRULIOLLE, Vincent (Eds.). The memory of State terrorism in the Southern Cone: Argentina, Chile, and Uruguay. Nem York: Palgrave Macmillan US, 2011. 